\title{
Comparison of different methods to limit short circuit currents in DC traction networks
}

\author{
Sam Breugelmans*, Willem Leterme ${ }^{\dagger}$, Dirk Van Hertem ${ }^{\dagger}$, Richard Marcelis $^{\circ}$ \\ ${ }^{*}$ TUC Rail, Belgium, ${ }^{\dagger}$ KU Leuven / EnergyVille, Belgium, ${ }^{\circ}$ Infrabel, Belgium \\ contact: sam.breugelmansatucrail.be
}

\begin{abstract}
In this paper, different methods to limit short circuit currents in DC traction networks are compared. Typically, DC traction networks are supplied by the AC grid by means of an uncontrolled diode bridge rectifier. In case of a low-impedance short circuit fault between catenary and rail, the fault current reaches a large value. For densely meshed networks the mechanical circuit breakers can become too slow. The methods studied are applying fault current limiters, faster interruption of fault currents and adding controlled rectifiers. The fault current limiters considered are a reactor and a superconducting fault current limiter (SFCL). For faster interruption of fault currents, a hybrid circuit breaker is investigated. Simulations show that the short circuit current can be limited considerably by installing limitation devices after the rectifiers, when the short circuit occurs close to a substation. Fast interruption of the fault or application of the SFCL results in the strongest reduction of the short circuit current.
\end{abstract}

\section{Introduction}

Traction networks are built in open air, which makes them very susceptible to faults. These faults can often lead to short circuit currents in the network. Due to the high infeed from the surrounding substations, the short circuit current can reach very high amplitudes. The faults can often not be avoided and the only remaining solution is to limit the short circuit currents.

As modern traction networks are more and more loaded, even more substations are installed in the network. This results in higher short circuit currents, which can cause considerable damage to the infrastructure or endanger human safety. The mechanical circuit breakers, which are used to interrupt the short circuit current, are sometimes too slow to overcome these problems.

Two main options exist to limit the short circuit current: limiting the current or interrupting faster, before the peak value is reached. Fault current limiters (FCLs) are often used in AC networks to limit short circuit currents [1]. The previous years a lot of effort has been put in the limitation of short circuit currents in DC networks [2], especially meant for the development of HVDC grids. Alternatively, some devices exist that interrupt a short circuit current much faster than mechanical circuit breakers [3,4].

This paper evaluates the applicability of a reactor, a faster circuit breaker, an SFCL and a controlled rectifier to limit short circuit currents in traction networks. Therefore the different devices are implemented after the rectifiers in the substations. The influence on the short circuit current is examined for every method.

Section 2 discusses the model of the network and its components used to test the effect of the different limitation methods. The model of the mechanical circuit breakers is given. In Section 3, the short circuit currents for the different methods are presented. Section 4 shows a case study for the implementation of the different methods in a real traction network. This section also discusses the necessary modifications to the protection settings. Finally Section 5 gives a conclusion.

\section{Traction network and short circuit current}

This section introduces the model used to simulate the traction network under fault conditions, using the software Matlab/Simulink.

\subsection{Traction network and modelling}

A traction network consists of many substations, which are interconnected with each other by the catenary lines and the rails. Every substation is equipped with two to four transformer rectifier groups, which are connected to the $3 \mathrm{kV}$ DC busbar of the substation. This busbar is the starting point of the feeder cables, which run towards the catenary lines. Every feeder is equipped with a mechanical circuit breaker. This circuit breaker has to interrupt short circuit currents. Current is supplied through the catenaries and returns via the rails. The traction network is unearthed to avoid stray currents. The construction of a DC traction network is treated more in detail in [5].

The following sections describe the modelling of the different components in the network. This study only considers a short circuit between the catenary and the rail, because these short circuits result in the highest short circuit currents.

\subsubsection{Substation model}

In practice, the substations can have different transformerrectifier groups installed. The rectifiers that are used are twelvepulse uncontrolled rectifiers, as illustrated in Figure 1.

The transformer model makes use of a model of uncoupled windings. All values used for the impedance of the transformers are shown in Table 2 of the Appendix. These values are derived from measurements of traction transformers with a short circuit voltage of $12 \%$.

The rectifier bridge model is built using ideal diodes. Through the use of diode models, the commutation losses due to overlap of the current in the different phases during the commutation is taken into account.

\subsubsection{Line model}

The catenary lines are approximated as a resistance $R_{\text {cat }}$ and an inductance $L_{c a t}$ connected in series (see Figure 1). The rails 


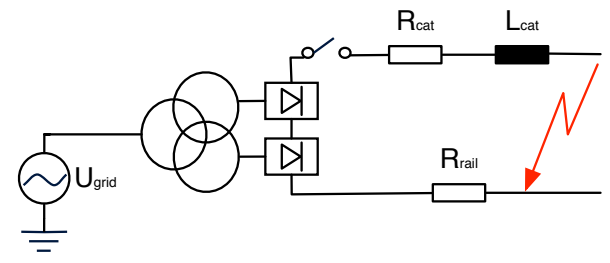

Figure 1: Representation of the traction network model.

are approximated as a resistance $R_{\text {rail }}$. All values used for the impedance of the catenary lines and rails are shown in Table 3 of the Appendix.

\subsubsection{Model for mechanical circuit breaker}

Electric arc models for circuit breakers are proposed in [6,7]. However, for this study, a simplified model for the circuit breakers is composed.

The circuit breaker is approximated by a linear rising voltage source, which represents the arc voltage $U_{a}$ in function of the time $t$ :

$$
U_{a}(t)=r\left(I_{S C 0}\right) \cdot\left(t-t_{0}\right) \text { for } t>t_{0} .
$$

$r$ is the slope of the rising voltage, which depends on the short circuit current $I_{S C 0}$ at the moment of interruption. The time $t_{0}$ is the time at which the arc voltage starts to rise. It consists of the time $t_{d e t}$ to detect the short circuit and the time $t_{\text {open }}$ before sufficient magnetic energy is stored to open the clamps of the circuit breaker (depends on $d i / d t$ ):

$$
t_{0}=t_{d e t}+t_{\text {open }}\left(\frac{d i}{d t}\right) .
$$

The arc voltage $U_{a}$ rises until it reaches a maximum value, which is proven by experiments [8]. When the voltage $U_{a}$, represented by (1), reaches the maximum value, the voltage remains constant. Figure 2 shows the arc voltage and the respective short circuit current as modelled. Figure 3 shows the dependence of the slope $r$ on the short circuit current $I_{S C 0}$ and the dependence of $t_{\text {open }}$ on $d i / d t$. These values are derived from experimental tests.
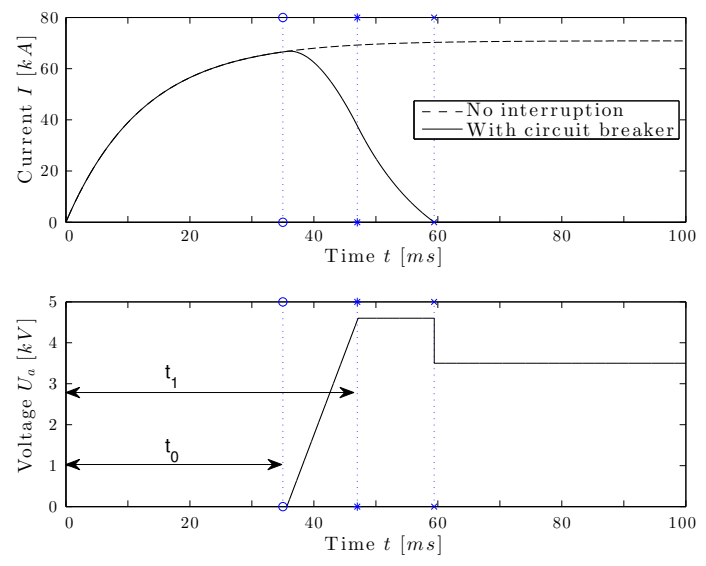

Figure 2: Arc voltage (bottom) and the respective short circuit current (top) using a mechanical circuit breaker.
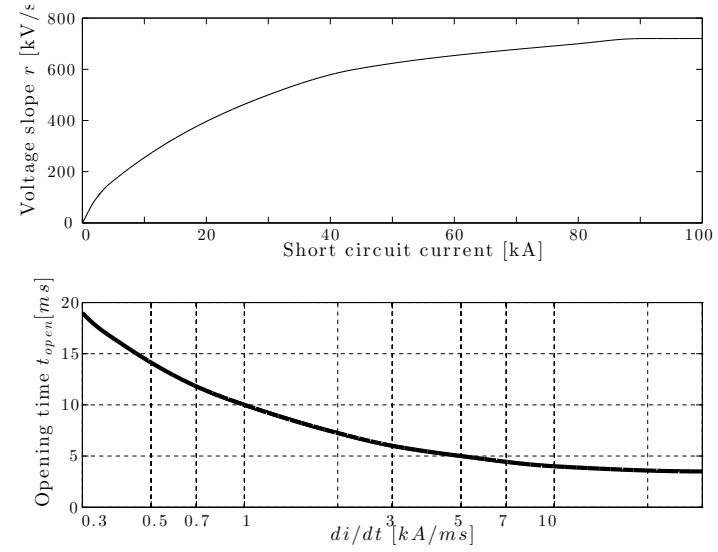

Figure 3: Voltage slope $r$ in function of short circuit current $I_{S C 0}$ at the moment the arc voltage starts to rise (top). Opening time $t_{\text {open }}$ in function of the initial $d i / d t$ (bottom).

Different types of protection criteria are used to detect the short circuit: a direct protection, calculation of $\Delta I$ and calculation of $d i / d t$. The direct protection is built-in in the circuit breaker and is triggered by the amplitude of the current. The $\Delta I$ and $d i / d t$ protection are provided by an external relay. These protections are necessary to distinguish a short circuit far from a substation from a high load current. These protection criteria are treated more in detail in [9]. The direct protection is most important for short circuits close to the substation. In the simplified network the direct protection threshold is set to $6000 \mathrm{~A}$.

\subsubsection{Network model}

Figure 4 shows a simplified traction network. It consists of five substations. Substation 1 is located in the centre and four substations are connected in star with substation 1 . Due to the strong parallel infeed, this configuration leads to high short circuit currents. The substations are connected by two parallel catenary lines with a length of $10 \mathrm{~km}$.

When a short circuit occurs, the short circuit current is fed by every surrounding substation. The contribution of the respective substation depends on the impedance between the substation and the short circuit.

The short circuit currents for a short circuit close to substation 1 and in the middle between substation 1 and substation 3 are studied. A short circuit close to a substation is dominated by the current from the converter. Its current waveforms are completely different from the waveforms for a short circuit far from a substation, where the transmission line limits. A short circuit current for a short circuit close to a substation has a much higher rate of rise and a higher peak value [10].

\subsection{Characteristic values for the short circuit}

The peak value of the short circuit current and the Joule-integral are chosen to characterize the short circuit. The peak value of the short circuit current determines the maximum forces on components. This current flows through the feeders and the circuit breaker needs to be able to interrupt it. The Joule-integral 


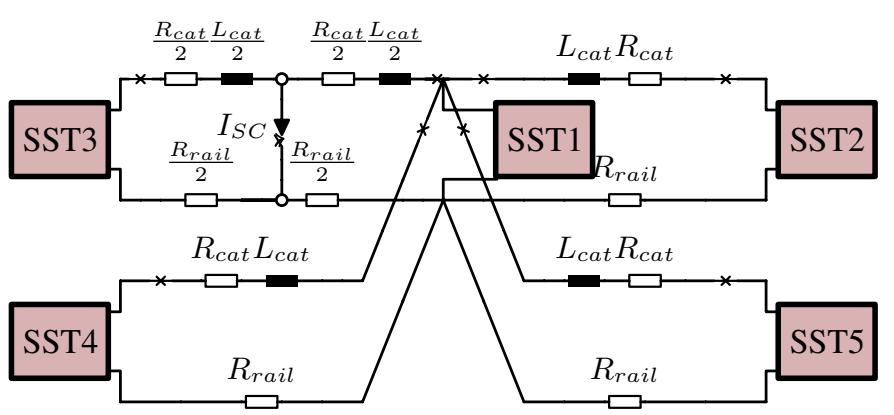

Figure 4: Simplified network (SST $=$ substation). The short circuit is depicted in the middle of substation 1 and 3.

is considered equal to:

$$
\text { Joule-integral }=\int I^{2} d t .
$$

The Joule-integral is characteristic for the heating of the cables and other equipment. Excessive heating leads to degradation of components and breakdown.

In the test case shown in Figure 4, the highest values for the peak current and the Joule-integral occur in the feeder cable near substation 1 (this feeder is the starting point of the catenary between substation 1 and substation 3). Because the current through this feeder is equal to the sum of the current from substation 1 and the three surrounding substations (2, 4 and 5). As a consequence, the limitation for the peak value of the short circuit current and the Joule-integral is most important in the feeder near substation 1 . The corresponding short circuit current in the feeder near substation 1 is shown in Figure 5.

\section{Implementation of different methods}

Figure 5 shows the short circuit currents for the implementation of the different methods to limit the short circuit current. The base case shows the short circuit current for the network described in Section 2. In this network the short circuit current is only interrupted by the mechanical circuit breakers.

Both passive and active devices are installed after the rectifier. A passive device limits the short circuit current automatically without any necessary actions. An active device needs a control signal to react when a short circuit occurs.

This section discusses the influence on the short circuit current for respectively a reactor of $3 \mathrm{mH}$, a fast circuit breaker, a superconducting fault current limiter (SFCL) and a controlled rectifier. These different devices are given the collective term current limiters, as they all aim to limit the short circuit current. The reactor and the SFCL are passive current limiters. The fast circuit breaker and the controlled rectifier are active current limiters.

\subsection{Reactor of $3 \mathbf{~ m H}$}

Reactors are already used to limit short circuit currents in AC networks [11]. In DC networks, the reactor $L_{\text {reactor }}$ enlarges the time constant of the short circuit current, hence the short
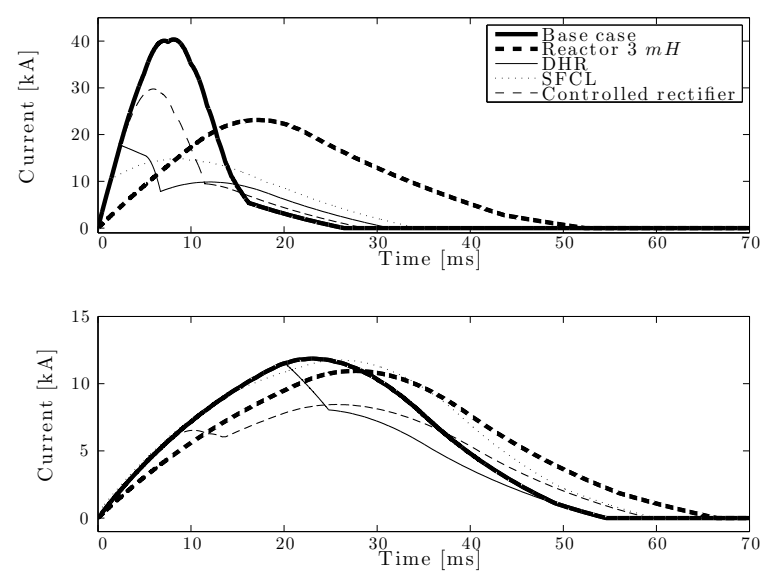

Figure 5: Short circuit current in the feeder near substation 1. The upper graph shows a short circuit close to substation 1 and the lower graph a short circuit far from substation 1 .

circuit current rises slower:

$$
\tau=\frac{L_{\text {cat }} \cdot l+L_{\text {reactor }}}{\left(R_{\text {cat }}+R_{\text {rail }}\right) \cdot l} .
$$

$l$ represents the length of the line. Compared to the base case, the current is lower at the moment the circuit breaker starts to open. As a consequence the peak value of the short circuit current decreases. The reactor only influences the transient behaviour of the short circuit current.

In this study a reactor with an inductance of $3 \mathrm{mH}$ is installed after each rectifier. The reactor is assumed to be ideal, so its resistance is neglected.

Figure 5 shows that the peak short circuit current decreases due to the slower rate of rise of the current. The reactor has a large influence for short circuits close to a substation. The peak current is diminished, but it takes longer before the current is totally extinguished. The total interruption time increases due to the enlargement of the time $t_{0}$ in (2) before the circuit breaker starts to open. In addition to this, the release of the total energy in the system takes longer, because of the additional energy stored in the reactor of $3 \mathrm{mH}$. This puts an additional strain on the circuit breaker. The reactor has a low influence on the short circuit current when the short circuit occurs further away from a substation, due to the low extra impedance of the reactor compared to the impedance of the catenary. The time constant in (3) hardly increases for short circuits far from the substation.

\subsection{Fast circuit breaker}

Circuit breakers that make use of power electronics can interrupt the short circuit currents much faster. However, solid state circuit breakers result in too much energy losses during normal operation. Hybrid circuit breakers are more feasible in traction networks, by combining a mechanical circuit breaker with power electronics. The fast circuit breaker can be used to interrupt very quickly the contribution to the short circuit current of the respective rectifier. These fast circuit breakers can make use of the same protection criteria as the mechanical circuit breakers in the feeders. Due to the larger amount of components than a 
mechanical circuit breaker, the probability that it fails is higher. The fast circuit breaker considered in this paper is the DHR [3] (see Figure 6).

Figure 5 shows that the short circuit current is limited considerably, when a short circuit occurs close to a substation. In this example the fast circuit breaker interrupts the contribution of substation $12 \mathrm{~ms}$ after the short circuit occurred. The rectifier of substation 1 is nearly immediately taken out of the circuit. At that time, the short circuit current still needs to be interrupted by the mechanical circuit breakers in the feeder. When the short circuit is taken out of the network, the fast circuit breaker can switch on again and put the rectifier again in the network. The reswitching process takes approximately $10 \mathrm{~s}$, due to the recharging of the capacitor in Figure 6.

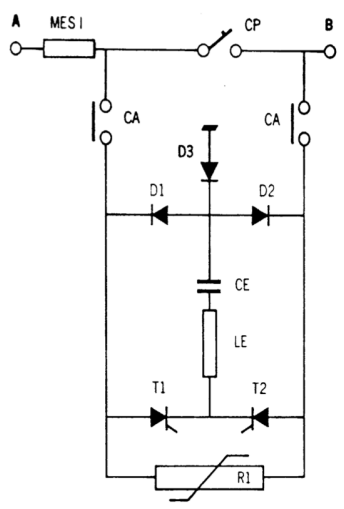

Figure 6: Electrical diagram of the DHR [3].

\subsection{SFCL}

A superconductive fault current limiter (SFCL) behaves as an ideal conductor during normal operation. When the current rises too much (due to a short circuit) the SFCL loses its superconductivity and becomes a normal conductor [12]. SFCLs are already used in certain networks to limit short circuit currents [13]. A resistive SFCL can be included into DC grids to limit short circuit currents. In normal operation the SFCL needs to be cooled continuously to maintain its superconductivity (to a temperature of $77 \mathrm{~K}$ ). The cooling machines needed for this are quite bulky and consume energy all the time.

A resistive SFCL is modelled by combining an electrical model and a thermal model. The electrical model is modelled as shown in $[14,15]$ and consists of three conducting states. The thermal model is modelled as in $[16,17]$.

The characteristics of the SFCL depend on the material that is used and its dimensions. The studied SFCL uses Bi2212 material. The section and length of the SFCL are determined, so it starts to limit the current when it exceeds $5000 \mathrm{~A}$.

Figure 5 shows that the short circuit current is limited considerably when the short circuit occurs close to a substation. When the current becomes too high, the SFCL after the rectifier loses its superconductivity and becomes a normal conductor. Hereby the contribution of the respective rectifier is reduced considerably.

\subsection{Controlled thyristor rectifier}

A controlled rectifier using thyristor rectifier bridges can control the output voltage and thereby the short circuit current [18]. The output voltage of the rectifier can be controlled by changing the delay angle $\alpha$ for the ignition of the thyristors [19].

The controlled rectifier keeps the delay angle $\alpha$ at $0^{\circ}$ during normal operation. The thyristor rectifier consequently behaves the same as a diode rectifier. When the current becomes higher than a certain set up value (equal to $5000 A$ in this example) the delay angle is put between $90^{\circ}$ and $140^{\circ}$ [19].

The passive rectifiers of substation 1 and 3 are replaced by controlled rectifiers. Figure 5 shows the corresponding short circuit currents for a delay angle $\alpha$ of $90^{\circ}$. Consequently the output voltage of the rectifier decreases and the corresponding short circuit current decreases. The short circuit current is limited both for a short circuit close to a substation as for a short circuit far from a substation.

\section{Case study}

In this section the methods shown in the previous section are implemented in a model of a real network. Figure 7 shows the traction network in the Brussels region, which consists of a lot of substations close to each other and interconnected by multiple catenary lines. As a consequence the equivalent impedance between the substations is very low, resulting in high short circuit currents. In this case study a short circuit is simulated at one of the six lines between Brussels-Midi and Forest (indicated on Figure 7). The direct protection of the circuit breakers in the feeders is adjusted to $5600 \mathrm{~A}$. The substation of BrusselsMidi is divided into two separate feeding substations. These feeding substations are linked by a bus coupler. When a short circuit occurs, the mechanical circuit breakers in the bus coupler separate the two parts of the substation from each other.

\subsection{Impact on short circuit currents}

In the base case, the short circuit current achieves peak values above $100 k A$ (see Figure 8 ). To reduce this peak current, the limitation methods are implemented after the rectifier of Brussels-Midi. The limitation devices are only installed in the substation of Brussels-Midi. The short circuit current is limited considerably for faults close to the substation of Brussels-Midi. The short circuit currents for a short circuit further away from Brussels-Midi (in the middle between Brussels-Midi and Forest) is barely influenced. Table 1 shows the results for the limitation of the peak short circuit current and Joule-integral when the short circuit occurs close to Brussels-Midi.

The implementation of the fast circuit breaker or the SFCL after the rectifier results in the highest limitation of the short circuit current. However, the short circuit current waveform is completely different (as shown in Figure 8). The reactor of $3 \mathrm{mH}$ can also limit the short circuit current considerably. It is a simple passive current limiter with a very high reliability. The controlled rectifier affects the short circuit current the least. 


\subsection{Impact on protection settings}

The protection settings of the different current limiting devices and the mechanical circuit breaker need to be chosen. For the active devices the protection settings of the device need to be adjusted. The passive devices need to be dimensioned well, to adjust its protection settings. The fast circuit breaker substitutes the mechanical circuit breaker, but the other devices still need the mechanical circuit breaker to interrupt the short circuit current. Hereby the fault current limiters can affect the protection settings of the mechanical circuit breakers.

The inductance of the reactor needs to be determined carefully. When it is chosen too high, the reactor stores too much energy that needs to be released. This enlarges the interruption time.

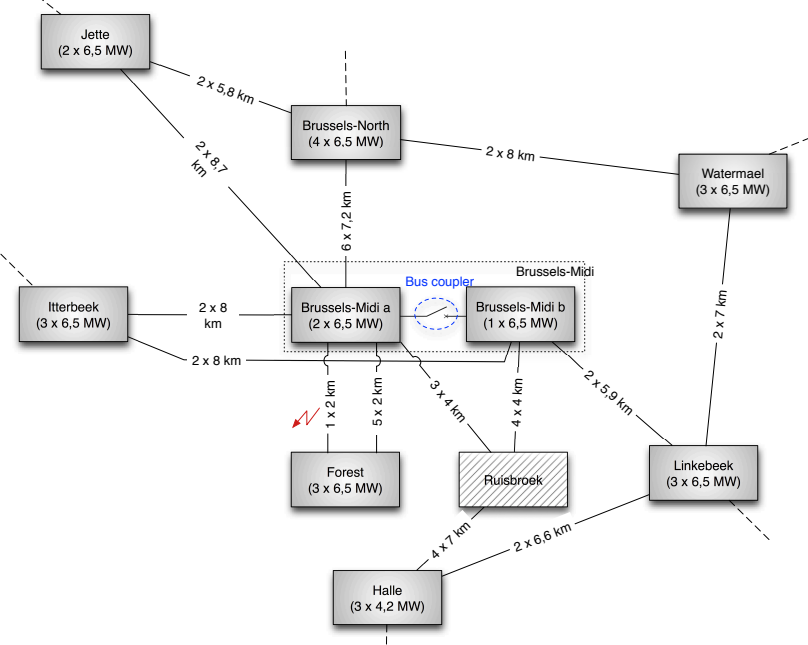

Figure 7: Traction network Brussels. Substations are shown with amount of transformer rectifier groups and corresponding power. The length and the amount of catenary lines between them is also shown. The short circuit is simulated on one of the six lines between Brussels-Midi and Forest.
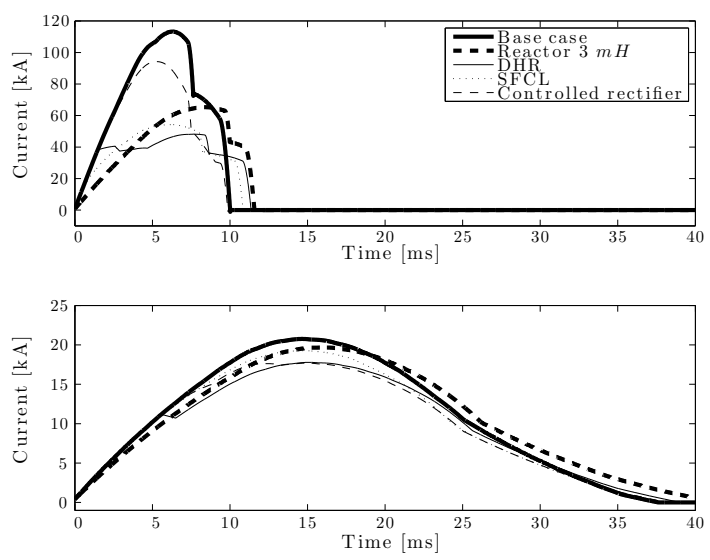

Figure 8: Short circuit current in the feeder near substation Brussels-Midi. The upper graph shows a short circuit close to substation Brussels-Midi and the lower graph a short circuit further away from substation Brussels-Midi.
The reactor only adds extra inductance, so the mechanical circuit breaker still has to interrupt the short circuit current. The settings for $d i / d t$ and $\Delta I$ can be set lower, due to the extra inductance of the reactor . Especially for short circuits far from a substation these settings are important.

The fast circuit breaker substitutes the mechanical circuit breaker and does not need many adjustments of the protection settings. A faster circuit breaker will not change the short circuit current waveform before the interruption process. Therefore the protection relays of the mechanical circuit breaker can be used. The SFCL can not easily adapt its settings, because the settings depend on the material properties and the dimensions. Besides the SFCL can only react on the amplitude of the short circuit current. It can not make a distinction between a short circuit far from a substation and a high load, by looking at the current waveform. Therefore it is necessary to use the SFCLs in addition with mechanical circuit breakers.

The controlled rectifier starts to limit the current when it exceeds a set up value. This value can be set lower than the direct protection value of the mechanical circuit breaker. Hereby the short circuit current is already weakened when the mechanical circuit breaker starts to interrupt.

\begin{tabular}{lrr}
\hline & Peak current & Joule-integral \\
\hline Base Case & $113,3 k A$ & $62,74 k A^{2} s$ \\
Reactor 3 mH & $57,7 \%$ & $41,4 \%$ \\
DHR & $42,3 \%$ & $27,0 \%$ \\
SFCL & $47,9 \%$ & $29,7 \%$ \\
Controlled rectifier & $83,2 \%$ & $66,0 \%$ \\
\hline
\end{tabular}

Table 1: Short circuit current and Joule-integral. The results for the different limitation devices installed after the rectifier are shown in percentages with respect to the base case.

\section{Conclusion}

This paper gives an overview of methods to limit the short circuit current in DC traction networks. First a simplified model was proposed to test the limitation of the short circuit currents for the different current limiters. A reduced model is proposed to represent the behaviour of the mechanical circuit breakers in every feeder. The different current limiters were modelled and included in the simplified traction network. The short circuit currents for the implementation of the different methods were compared with each other. The paper also included a case study which showed the results for the short circuit current when the different methods are implemented in a real network.

In this study, the different limitation devices were installed at the rectifier. The influence of a reactor, fast circuit breaker, SFCL and controlled rectifier were compared. The case study demonstrated that short circuit currents for a short circuit close to a substation reach very high values, which can be limited considerably by the different limitation devices. When the short circuit occurs far from a substation the current is only limited to a small extent.

Very fast interruption of the current contribution of the rectifier with a fast circuit breaker results in the strongest limitation of 
the short circuit current. A reactor can also be installed after the rectifier to limit short circuit currents considerably.

Future work needs to be done to determine good parameters for the protection devices. The best combination of the protection settings for the current limitation device and the mechanical circuit breaker can be investigated.

\section{Appendix}

\begin{tabular}{llll}
\hline & $\begin{array}{l}\text { Phase to } \\
\text { phase } \\
\text { voltage } U \\
{[\mathbf{k V}]}\end{array}$ & $\begin{array}{l}\text { Resistance } \\
R \text { [p.u.] }\end{array}$ & $\begin{array}{l}\text { Inductance } \\
L \text { [p.u.] }\end{array}$ \\
\hline Winding 1 (Y) & 30 & 0,00108 & 0,10838 \\
Winding 2 (d11) & 1,281 & 0,00574 & 0,01827 \\
Winding 3 (y) & 1,281 & 0,00648 & 0,01926 \\
\hline
\end{tabular}

Table 2: Voltage, resistance and inductance for the three windings of the transformer. $S_{\text {base }}$ is equal to the apparent power of the transformer (10 MVA), $U_{\text {base }}$ is equal to the voltage of the corresponding winding.

\begin{tabular}{lrr}
\hline & $\begin{array}{l}\text { Resistance } R \\
{[\mathrm{~m} \Omega / \mathrm{km}]}\end{array}$ & $\begin{array}{l}\text { Inductance } L \\
{[\mathrm{mH} / \mathrm{km}]}\end{array}$ \\
\hline Catenary & 55,4 & 1,4 \\
Rail & 2,5 & $/$ \\
\hline
\end{tabular}

Table 3: Specific resistances and inductances of the catenary and the rail.

\section{Acknowledgements}

The authors would like to thank the people of the substation division of Infrabel, the Belgian railway operator, for their support and the provision of all the necessary information.

The work of Willem Leterme is supported by the FWO (Research Foundation Flanders).

This work has been fulfilled in line of a M.Sc. Thesis within the master in energy program at the KU Leuven.

\section{References}

[1] H. Schmitt, "Fault current limiters report on the activities of cigre wg a3. 16," in Power Engineering Society General Meeting. IEEE, 2006, 5 pages.

[2] S. Kulkarni and S. Santoso, "Interrupting short-circuit direct current using an ac circuit breaker in series with a reactor," Advances in Power Electronics, vol. 2012, no. 805958, 2012, 14 pages.

[3] H. Bonhomme, "Disjoncteur hyper-rapide à courant continu," Patent, ACEC s.a., May 1993. [Online]. Available: http://www.google.com/patents/EP0272349B1?cl=fr

[4] J.-M. Meyer and A. Rufer, "A dc hybrid circuit breaker with ultra-fast contact opening and integrated gatecommutated thyristors (igcts)," IEEE Transactions on Power Delivery, vol. 21, no. 2, pp. 646-651, 2006.

[5] R. Hill, "Electric railway traction. part 3: Traction power supplies," Power Engineering Journal, vol. 8, no. 6, pp. 275-286, 1994.
[6] K.-J. Tseng, Y. Wang, and D. Vilathgamuwa, "An experimentally verified hybrid cassie-mayr electric arc model for power electronics simulations," IEEE Transactions on Power Electronics, vol. 12, no. 3, pp. 429-436, 1997.

[7] J. Guardado, S. Maximov, E. Melgoza, J. Naredo, and P. Moreno, "An improved arc model before current zero based on the combined mayr and cassie arc models," IEEE Transactions on Power Delivery, vol. 20, no. 1, pp. 138142, 2005.

[8] ABB, ABB Circuit breakers for direct current applications, ABB, Sep. 2007.

[9] D. Knights, "Protection for dc substations and ac track feeder stations," in 3rd IET Professional Development Course on Railway Electrification Infrastructure and Systems, May 2007, pp. $71-80$.

[10] W. Braun, M. Dirauf, and E. Schneider, "Bahnausrüstungbemessung von potenzialausgleichsleitern auf bahnfahrzeugen und in ortsfesten anlagen," Elektrische Bahnen, vol. 108, no. 1, p. 65, 2010.

[11] F. Kierstead and H. O. Stephens, "Current-limiting reactors their design, installation and operation," Transactions of the American Institute of Electrical Engineers, vol. 43, pp. 902-913, 1924.

[12] A. Hobl, S. Elschner, J. Bock, S. Kramer, C. Janke, and J. Schramm, "Superconducting fault current limiters: a new tool for the grid of the future," in CIRED 2012 Workshop: Integration of Renewables into the Distribution Grid, Jan. 2012, pp. 296-301.

[13] J. Bock, A. Hobl, S. Krämer, M. Bludau, J. Schramm, C. Jänke, M. Rikel, and S. Elschner, "Nexans' superconducting fault current limiters for medium voltage applications-status and prospects," in 21st International Conference on Electricity Distribution, no. 0352, 2011, pp. 6-9.

[14] P. Manohar and W. Ahmed, "Superconducting fault current limiter to mitigate the effect of dc line fault in VSC-HVDC system," in International Conference on Power, Signals, Controls and Computation (EPSCICON), 2012, pp. 1-6.

[15] L. Ye and K.-P. Juengst, "Modeling and simulation of high temperature resistive superconducting fault current limiters," IEEE Transactions on Applied Superconductivity, vol. 14, no. 2, pp. 839-842, 2004.

[16] S. Nemdili and S. Belkhiat, "Modeling and simulation of resistive superconducting fault-current limiters," Journal of Superconductivity and Novel Magnetism, vol. 25, no. 7, pp. 2351-2356, 2012.

[17] M. Stemmle, B. R. Oswald, F. Breuer, S. Elschner, and M. Noe, "Simulation model for a novel superconducting fault current limiter," Journal of Physics: Conference Series, vol. 43, no. 1, p. 954, 2006. [Online]. Available: http://stacks.iop.org/1742-6596/43/i=1/a=233

[18] P. Rault, X. Guillaud, F. Colas, and S. Nguefeu, "Challenges when operating dc grids," in Het offshore netwerk, de Supergrid. Revue E tijdschrift, Dec. 2012, no. 4, pp. $30-35$.

[19] P. Kundur, N. Balu, and M. Lauby, Power system stability and control. McGraw-Hill, 1994. 